\title{
Flashbacks of a Mathematical Life
}

\author{
Alexandra Bellow
}

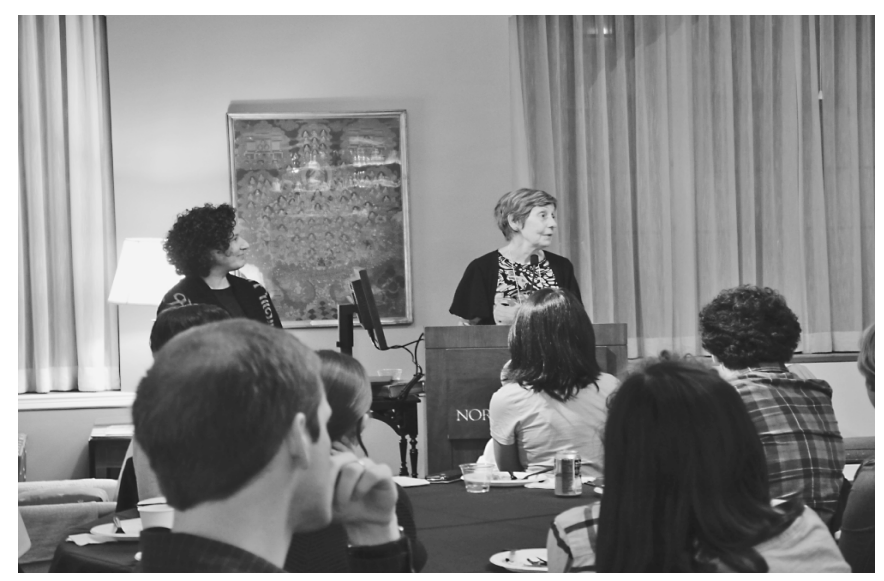

Bryna Kra (left) after introducing Alexandra Bellow for an after-dinner address.

I was born in Bucharest, Romania. Bucharest, that enigmatic city at the gates of the Orient that some people used to call the Little Paris of Eastern Europe. My parents were both physicians: my father was a brain surgeon, my mother a child psychiatrist. My mother was also keenly interested in child education, particularly the teaching of arithmetic. She had her own ideas on the subject, devised amusing games, and loved experimenting on me. I was a willing, eager guinea pig, and before I knew it, I had fallen in love with mathematics.

My mother was a great admirer of Hypatia, this extraordinary woman philosopher and mathematician of the fifth century, who taught in Egypt at the Academy in Alexandria. What my mother omitted to tell me was that Hypatia came to a very violent, brutal end, torn to pieces by a mob-probably because she was a woman, because she

Alexandra Bellow is a retired professor of mathematics at Northwestern University. Her email address is a_bel1ow@math. northwestern. edu.

For permission to reprint this article, please contact:

reprint-permission@ams.org.

DOI: http://dx.doi.org/10.1090/noti1417 was so learned, so admired, and she dared to be different. Her death marked the beginning of the end of Alexandria as a great center of learning in antiquity. Hypatia never ceased to fascinate and inspire: there are novels, historical accounts, and dramatizations of her life, including the 2009 movie Agora.

Both my parents held mathematics in high esteem. As a civil engineer, my maternal grandfather had built highways and bridges in Asia Minor and had also taught high school mathematics. My grandfather believed that girls as well as boys should be given the best education possible: wealth, social standing, political power can come and go, swept away by upheavals, wars, revolutions, but a "well furnished mind"-as he put it-is something that nobody can take away from you.

My mother wanted to become a civil engineer like her father, but at the end of World War I women were not admitted to the Polytechnic Institute in Bucharest. She petitioned the minister of education, but to no avail. So she studied medicine instead.

My father died when I was ten-years-old. A few years later I informed my mother that I wanted to study math and become a mathematician. She did not seem a bit surprised; she may even have been secretly pleased.

I would like to say a few words about the role that mathematics played in my life, and I shall do this by sketching my training as a mathematician.

My last year in high school, 1953, was my definitive, formative year. It coincided with the peak of the Stalinist Terror in Romania and in the whole Eastern Bloc. It also coincided with my mother's political disgrace. This was very likely triggered by the fact that my mother, as minister of health in 1946-48, had asked the West for help, and the West had sent food and medical supplies to war-devastated Romania. She was accused of being a cosmopolite. The specter of a purge trial, arrest, and possible annihilation hung over my mother and me for quite some time.

Fortunately, in the last years of high school, I had a superb math teacher. She was demanding but fair, small, 
wiry, fearless, and determined to give me the support I needed. That's how I survived one of the darkest periods of my life; that's how I came to detest ideologies of all stripes and to feel that mathematics, perhaps more than any other discipline, can endow you with the independence of spirit needed to resist political pressures and to follow your intellectual passions. The beauty of mathematics, its clarity, precision, and elegance are universally acknowledged. Mathematical work has to be honest, "not from any sense of moral superiority, but simply because in Mathematics you cannot get away with fakery," as Littlewood, the great English mathematician of the twentieth century, put it.

I graduated from high school at the top of my class in June 1953 and was admitted to the University of Bucharest, the Department of Mathematics, in the fall. At the university I was awarded the Republican Fellowship and I finished my studies in three years instead of four, graduating with the equivalent of a master's degree in mathematics. But I have to admit that the transition from high school mathematics to mathematical analysis-the firstyear course at the university - was downright challenging. I really struggled during the first two months. The course was taught by Professor Cassius Ionescu Tulcea in a radical new way, starting from a few axioms and elaborating the theory in the most abstract, most economical, most general framework, without recourse to pictures but only to a few basic examples: this was the new avant-garde style of French mathematics, the "Bourbaki" style. In parallel with the mathematical analysis course, Professor Solomon Marcus ran the analysis seminar, and in his spirited way exposed us to a wealth of concrete examples and problems that complemented and enhanced the theory.

At first I was C. Ionescu Tulcea's student, later I became his wife, and later still his collaborator. We wrote quite a number of papers together as well as a book, a research monograph on lifting theory. He was older, an established mathematician, and he received an invitation to participate in a special two-year program in functional analysis organized at Yale University. It was a great piece of good luck that after six months of very anxious waiting, in October 1957 we were allowed to leave. We were both given passports and we left the next day, leaving behind family and friends but also the suffocating feeling of existence in a country with sealed borders.

What struck me most when we reached the United States were the perfect strangers in the street who would smile and even say hello to me. What an extraordinary country, I thought: people leave their home in the morning with smiles on their faces and confidence in the future....

I was admitted to the $\mathrm{PhD}$ program in the math department at Yale, soon after we arrived in the fall of 1957, and I got my doctorate in 1959, just before I turned twentyfour. In the beginning I had a hard time communicating with the Oxford English and grammar that my aunt had so scrupulously taught me in Bucharest. It is no wonder that I ended up choosing Shizuo Kakutani for my thesis advisor: his English was straightforward, without colloquial expressions, and his mathematics beautiful. My classmates and colleagues used to tease me later that I learned to speak American English with a singsong Japanese accent.
The math department at Yale in those days was a male preserve par excellence. There were very few women among the graduate students in math at Yale and no woman on the faculty. Consequently female moral support, which could have been invaluable, was nonexistent; caucus groups and social media were still far into the future. I spent a lot of time talking to my husband but was otherwise in virtual isolation, studying math, deconstructing and rearranging my English. But the patronizing attitude of my male classmates lasted only until I gave my first seminar talk. After that I was treated with respect.

Kakutani was famous already for his fixed-point theorems. His fixed-point theorems involving set-valued functions, also called correspondences, were used later by mathematical economists who were awarded the Nobel Prize in Economics: Kenneth Arrow (Nobel 1972), Gérard Debreu (Nobel 1983), and John Forbes Nash (Nobel 1994).

It was a case of serendipity that I found an interesting problem to work on while browsing in the library, so I did not have to ask Kakutani for a thesis topic. He was patient and kind with me, generous with his time and sharp mathematical insights. Here is an epiphany from that period: I had been stuck in my work for a few weeks, and I remember the exhilarating moment when, in the library, I came across Szegö's theorem on power series with coefficients from a finite alphabet. It was exactly the theorem I needed to complete my proof. I felt like a prospector who had worked hard, overcome long periods of frustration, and

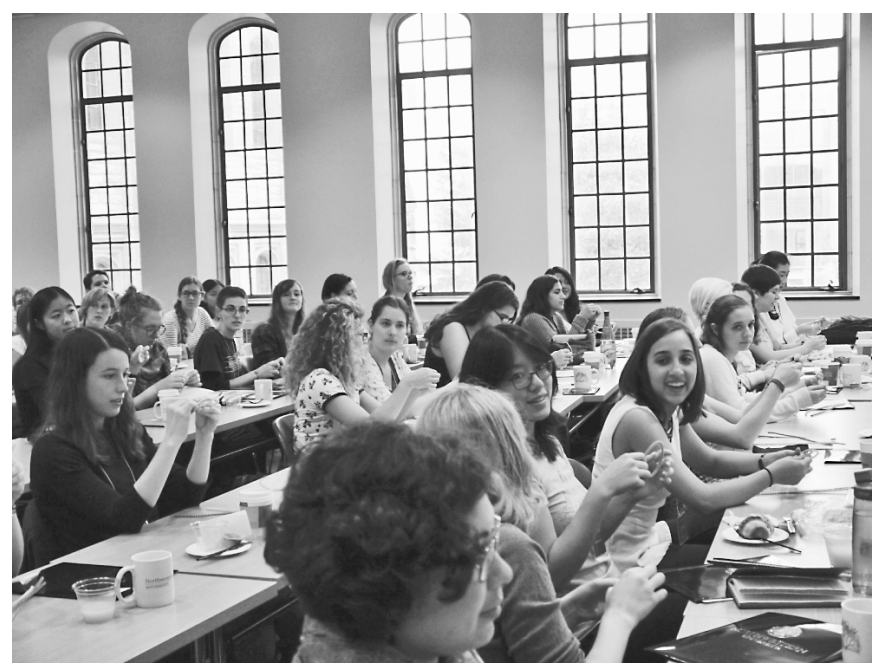

Students work with pipe cleaners during a lecture on knots by Eric Zaslow.

finally struck gold. It was an unforgettable moment, an existential experience....

I was thirty-two-years-old in 1967 when Ralph Boas, the chairman of the math department at Northwestern, made me an offer that dramatically and definitively changed the course of my life. This is how I became the first woman full professor in the math department at Northwestern. Ralph Boas, the legendary chairman, also broke a second barrier, namely, the anti-nepotism rule, for my husband at that time was already on the faculty, a full professor. I remained at Northwestern for the rest of my academic 
career, for nearly three decades, teaching and doing research.

My mathematical training did not end with my doctorate, of course. My main areas of interest in mathematics were ergodic theory and probability. In the early days, before the advent of the Internet, research was often a

\section{Mathematics has been for me a source of joy, of comfort and solace in times of crisis, of independence and strength}

solitary enterprise and if done in collaboration, required the presence of other mathematicians. I was fortunate to meet a number of wonderful mathematicians, and I was grateful to Northwestern University for allowing me to take a leave of absence whenever I needed to interact with mathematicians elsewhere. I spent time as a visiting professor at many other institutions, such as the University of Minnesota, MIT, Brandeis, Caltech, the University of Victoria (BC), UCLA, Hebrew University (Jerusalem), and Goettingen University (Germany).

By and large, my personal and my mathematical life have been deeply intertwined, even during the exotic eleven years when I was married to my second husband, the writer and Nobel Prize winner Saul Bellow. This marriage upended my rather austere lifestyle, opened up all sorts of new vistas. There were wonderful rewards, such as discovering the language of Shakespeare and the King James Bible, and the fairy-tale charm of the Nobel festivities in Stockholm in 1976, when Saul got the Nobel Prize. I often felt identified with the Cheshire Cat, one of Saul's favorite characters from Alice's Adventures in Wonderland, only I was not sure whether I was "the cat without the grin", or "the grin without the cat"... But balancing a career in mathematics and marriage to a writer was high voltage, and the marriage came to an end.

My third husband was the eminent Argentine-American mathematician Alberto Calderón. The decade of the nineties was for me a period of great personal happiness and infinite mathematical possibilities. This was the legacy that Alberto left behind when he unexpectedly died not long after I had retired from Northwestern. This, the dinners "flowing with tango music and Malbec wine," and many other things.

When all is said and done, Why mathematics? Why graduate studies in mathematics? Why an academic career in mathematics? I can only tell you what my personal experience has been. By and large, mathematics has been for me a source of joy, of comfort and solace in times of crisis, of independence and strength. The freedom to

\section{The GROW Conference for Women Undergraduates}

On October 24-25, 2015, the Department of Mathematics at Northwestern University hosted a conference for women undergraduates in the mathematical sciences. Lead organizer Bryna Kra developed the idea of the conference after years of frustration at declining numbers of women applying to graduate school. The event was designed with a single goal: to encourage women studying mathematics in the United States to continue their mathematical education at the graduate level. The conference, coorganized by Kra, Laura DeMarco, and Ezra Getzler, was called Graduate Research Opportunities for Women (GROW), and the acronym sums up the long-term goals for this meeting and its successors.

The inaugural GROW was a mix of research talks, panel discussions, mentoring sessions, and networking opportunities. The conference attracted fifty undergraduates selected from almost two hundred applicants from across the mathematical sciences: pure and applied mathematics, statistics, and mathematical biology. Students came from as far as Puerto Rico and California and as near as Chicago and Wisconsin. Participants included first-year students and seniors and a few recent graduates, representing forty different undergraduate institutions, a wide variety of backgrounds, and several students who were the first generation of their families to attend college.

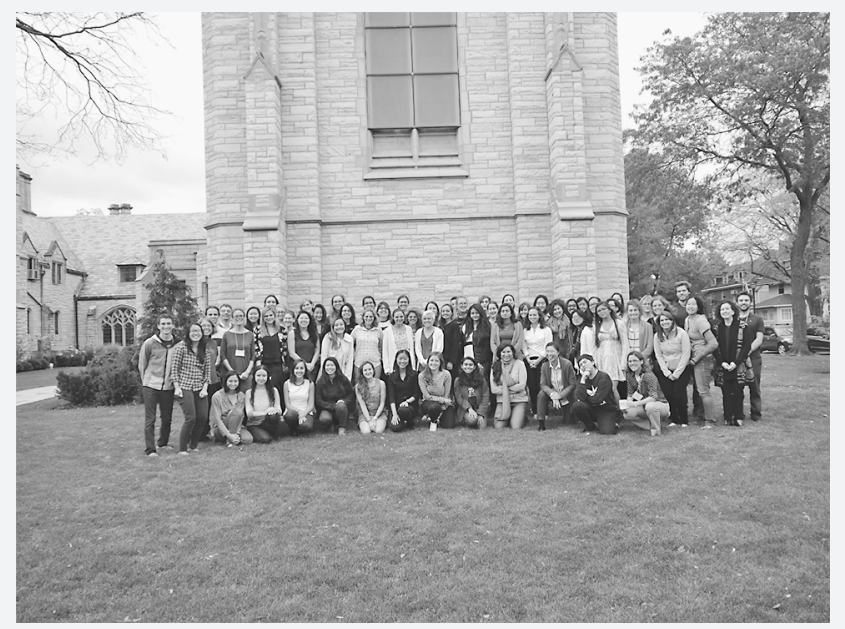

A highlight of the event was the Saturday evening address by Alexandra Bellow (a condensed version of which is included here). She kept the audience spellbound for over half an hour with stories from her childhood, career ups and downs, and the role mathematics played in her life.

Google "GROW math conference" for more information. This year's conference will be October 15-16, 2016.

work on any math problem or project I chose, the freedom to travel wherever the spirit moved me during the long summer vacations were privileges that a life with math in academia has offered me. 


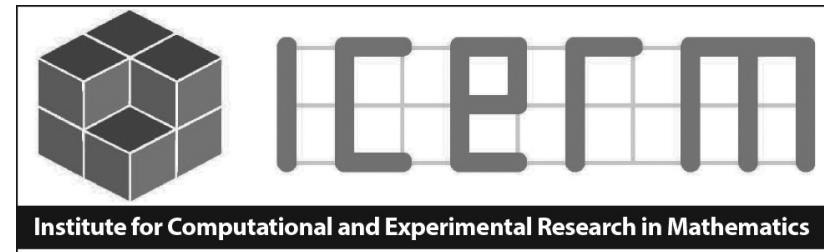

FALL SEMESTER 2017

These workshops are affiliated with ICERM's Fall 2017 semester program Mathematical and Computational Challenges in Radar and Seismic Reconstruction running September 6 through December 8, 2017.

SEPTEMBER 25 - 29, 2017: WAVES AND IMAGING IN RANDOM MEDIA Wave propagation and imaging in complex media is an interdisciplinary area in applied mathematics, with roots in hyperbolic partial differential equations, probability theory, statistics, optimization, and numerical analysis. It has a wide range of applications, including not only radar and seismic reconstruction but also many others, such as laser beam propagation through clouds, light propagation through the atmosphere in astronomy, secure communications in scattering media, medical imaging, and nondestructive testing of materials. Organizers: Josselin Garnier, University Paris Diderot; Kui Ren, University of Texas; Chrysoula Tsogka, University of Crete

OCTOBER 16 - 20, 2017: MATHEMATICAL AND COMPUTATIONAL ASPECTS OF RADAR IMAGING

This workshop will bring together mathematicians and radar practitioners to address a variety of issues at the forefront of mathematical and computational research in radar imaging. Some of the topics planned include shadow analysis and exploitation, interferometry, polarimetry, micro-Doppler analysis, through-the-wall imaging, noise radar, compressive sensing, inverse synthetic-aperture radar, moving target identification, quantum radar, multi-sensor radar systems, waveform design, syntheticaperture radiometry, passive sensing, tracking, automatic target recognition, over-the-horizon radar, ground-penetrating radar, and Fourier integral operators in radar imaging. Organizers: Margaret Cheney, Colorado State University; Armin Doerry, Sandia National Laboritories; Eric Mokole, U.S. Naval Research Laboratory (Ret); Frank Robey, MIT Lincoln Laboratory

NOVEMBER 6 - 10, 2017: RECENT ADVANCES IN SEISMIC MODELING AND INVERSION: FROM ANALYSIS TO APPLICATIONS

This workshop will bring together academic and industrial researchers with the goal of addressing some of the key challenges in the analysis of seismic inverse problems, with emphases on reconstruction, big data and fast algorithms. We aim to facilitate interactions among scientists addressing all aspects of this problem, from analysts addressing such questions as stability and uniqueness through geophysicists developing new acquisition systems and applying cutting-edge ideas to field data sets. The workshop will place particular emphasis on fast algorithms that address the unique big data requirements of seismic imaging from the reservoir to whole-Earth scale. Organizers: Maarten de Hoop, Rice University; Alison Malcolm, Memorial University of Newfoundland; Alexander Mamanov, University of Houston; Vladimir Druskin, Schlumberger Doll Research; Lexing Ying, Stanford University

Learn more about these workshops at: icerm.brown.edu.

Ways to participate:

Propose a:

- semester program

- topical workshop

- small group research program

- summer undergrad program

Apply for a:

- semester program or workshop

- postdoctoral fellowship

Become an:

- academic or corporate sponsor
About ICERM: The Institute for Computational and Experimental Research in Mathematics is a National Science Foundation Mathematics Institute at Brown University in Providence, Rl. icerm.brown.edu

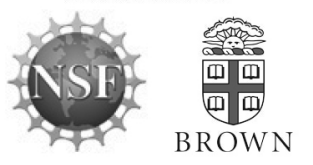

Still, even in this day and age when science and technology have made such incredible strides, you come across people who look at you with a mixture of fascination and dread when they find out that you are a mathematician. Such people will be surprised to learn that mathematics is a way of thinking. That mathematics can lead you to structures and patterns of unsurpassed beauty. And that when you prove a beautiful theorem, you are, according to the ancient Greeks, offering your audience a spectacle. ${ }^{1}$

\section{Credits}

All photos are courtesy of Bryna Kra.

\section{ABOUT THE AUTHOR}

Born in Bucharest, Romania, Alexandra Bellow completed a masters in mathematics at the University of Bucharest and her PhD at Yale University under the direction of Shizuo Kakutani. She was appointed professor of mathematics in the Department of Mathematics at Northwestern University in fall 1967, and she was the first woman full professor in the department. Her research was in ergodic theory and probability, and she stayed at Northwestern until her retirement in 1996. She remains an active figure in the department, and an annual lecture series was recently named in her honor. 